\title{
Some Recent Developments in the Theory of Nonlinear Singular Integral Equations ${ }^{1}$ )

\author{
L. V. WOLFERSDORF
}

Es -wird über einige kürzliche Untersuchungen sowjetischer Mathematiker und des Autors zu nichítlinearen singulären Integral- und Integrodifferential-Gleichungen vom Cauchyschen und Hilbertschen Typ berichtet, welche große Nichtlinearitäten enthalten.

Сообщаетсл о некоторџх недавних исследованиях советских математиқов и автора к нелинейным сингуляриы иттегральным и интегро-дифференциальным уравнениям типа fiши и Гильберта, которые содержают большие нелинейности.

We report on some recent investigations by Soviet mathematicians and the author about nonlinear singular integral and integro-differential equations of Cauchy, and Hilbert type involving large nonlinearities.

\section{Introduction}

Nonlinear singular integral and integro-differential equations involving the Cauchy operator

$$
(S u),(x)=\frac{1}{\pi} \int_{-a}^{a} \frac{u(\xi)}{\xi-x} d \xi, \quad-a \leqq x \leqq a,
$$

or the Hilbert operator

$$
(H u)(s)=\frac{1}{2 \pi} \int_{-\pi}^{\pi} u(\sigma) \cot \frac{\sigma:-s}{2} d \sigma, \quad-\pi \leqq s \leqq \pi,
$$

have been considered for a long time. We refer to the well-known treatise on integral equations by Pogorzelski [22], the recent monograph by Guseinov and MukHTAROV [13], and the recent survey article [14]. Moreover, we point out to the monographs by BIRKhoff and Zarantonello [10] (cf. also the survey article by Pykhteev [23]) and GAIER [11] for the occurrence and the investigation of particular equations of this kind in hydrodynamics and the theory of conformal mapping, respectively. But until recently the general theory of such equations was developed almost entirely for equations with a sufficiently small parameter before the nonlinear part.

- In this paper we report on some recent existence results for equations of this type without such severe smallness assumptions on the nonlinearities. These results by Soviet mathematicians and the author were obtained by means of various methods of nonlinear functional analysis (methods of monotone operator theory, application of nonlocal implicit function theorem, novel application of Schauder's fixed point theorem). Some minor till now unpublished results of the author are also incorporated in the paper.

1) Vortrag auf der Konferenz „Complex Analysis“ (s. Z. Anal. Anw, H. 2 (1986)). 
We remark that in recent times great efforts were made in applying numerical methods for the solution of nonlinear singular integral equations, too. But we will not deal with this topic here.

\section{Methods of monotone operator theory}

\section{a) Integral equations}

The operator $S$ is a linear bounded operator from $L_{p}=L_{p}(-a, a), p \geqq 2$, into $L_{q}, 1 / p+1 / q=1$, satisfying the relation

$$
(S u, u)=\int_{-a}^{a}(S u) \dot{(x)} u(x) d x=0 \text { for } u \in L_{p}, \quad \text { } \quad p \geqq 2 .
$$

Therefore, for any $\lambda \in \mathbf{K}$ the operator $\lambda S$ is a linear continuous monotone mapping from $L_{p}, p \geqq 2$, into $L_{q}$. Let $\varphi(x, u)$ be a monotone, C(arathéodory)-function on $[-a, a] \times \mathbf{R}$, i.e., $\varphi(x, u)$. is continuous and non-decreasing in $u \in \mathbf{R}$ for almost all $x \in[-a, a]$ and measurable in $x \in[-a, a]$ for all $u \in \mathbf{R}$. Further, let $\varphi(x, u)$ fulfil the inequality

$$
|\varphi(x, u)| \leqq A(x)+B|u|^{q-1},
$$

where $A \in L_{p}, B>0$. Then the Nemytskyi operator associated with the function $\varphi$ is a bounded, continuous monotone mapping from $L_{q}$ into $L_{p}$. If, moreover, $\varphi$ satisfies the condition

$$
u \varphi(x, u) \geqq C|u|^{q}-D(x)
$$

where $C>0, D \in L_{1}$ the Nemytskyi operator is also coercive.

If (3), (4) are fulfilled, the basic principle of monotone operator theory by Browder , and Minty yields the existence of a solution $u \in L_{q}$ of the equation

$$
u+\lambda \dot{S} \varphi(\cdot, u)=f
$$

for any $\lambda \in \mathbf{R}, f \in L_{q}[17]$. By a theorem of Brézis and Browder on Hammerstein operator equations in spaces of summable functions a unique solution $u$ of $(5)$ already exists if only (3) is satisfied. The cocrcivity condition (4) can be left out $[26,8]$.

Let the monotone C-function $\psi(x, u)$ fulfil the assumptions (3), (4) with $p \geqq 2$ instead of $q$. Then, again by the basic' principle of monotone operator theory, the existence of a unique solution $u \in L_{p}$ of the equation

$$
u+\lambda S u+\psi^{\prime}(\cdot, u)=g,
$$

for any $\lambda \in \mathbf{R}, g \in L_{q}$ follows [12,13]. With the help of the main theorem of maximal monotone operators by Browder this existence result can be extended to equations

$$
\chi(\cdot, u)+\psi(\cdot, u)+\lambda S u=g
$$

where $\chi(x, u)$ is an arbitrary (strictly) monotone C-function satisfying merely the condition $\chi(\cdot, 0) \in L_{q}[26]$.

The basic principle of monotone operator theory can further be used to prove the existence of a unique solution $u \in \cdot I_{p}, p \geqq 2$, of the equation

$$
u+\lambda \varphi(\cdot, S u)=h
$$


for any $\lambda \in \mathbf{R}, h \in \dot{L}_{p}$, where the strictly monotone C-function satisfies (3), (4) [8]; cf. also [17] for the case $1<p \leqq 2$.

Finally, the existence theorem for the equation (6), also remains valid if $1<p<2$, - where the first term $u$ in (6) can be replaced by $\beta u$ with a nonnegative bounded measurable function $\beta$ on $[-a, a]$. For proving this the operator $\beta u+\lambda S u$ is considered as unbounded monotone mapping from $L_{p}$ into $L_{q}$ with domain $L_{q}$. By a. theorem of Brézis and Browder this napping has a maximal monotone extension. Then, again the main theorem of maximal monotone operators is uséd [27].

All the mentioned results hold in corresponding weighted Lebesgue spaces $L_{p}(\varrho)$, $p \geqq 2$, with weights $\varrho(x)=(a-x)^{\gamma} \cdot(x+a)^{\delta},-1<\gamma, \delta<p-1$, and $L_{q}(\sigma)$, $\sigma(x)=\varrho(x)^{1-q}$, too $[12,13,26,8]$. Further, the Cauchy operator can be replaced by more general operators of the form

$$
\frac{b(x)}{\pi} \int_{-a}^{a} \frac{b(y) u(y)}{y-x} d y, \quad-\frac{1}{\pi} \int_{-a}^{a} \frac{[d(x)+d(y)] u(y)}{y-x} d y
$$

with suitable summable functions $b$ and $d$, respectively, (and by finite sums of them) and, moreover, by corresponding operators on the whole real axis $[2-8,26]$. Furthermore, related systems of integral equations have been dealt with in [3-7, 26].

By applying inversion formulas'like

$$
S_{0} S u=u \text { for } u \in L_{p}, \quad p>2,
$$

where the operator $S_{0}$ is defined by

$$
\left(S_{0} u\right)(x)=-r(x) S\left[r^{-1} u\right](x), \quad r(x) \doteq \sqrt{a^{2}-x^{2}}
$$

from the above existence theorems for the equations (5)-(8) one obtains existence . theorems for equations involving the operator $S_{0}$ and related ones $[17,26,27]$.

Finally, related rèsults hold for equations with the Hilbert operator $(2)$ in $L_{p}(-\pi, \pi)$ $p \geqq 2,[1,26]$ since also

$$
(H u, u)=\int_{-\pi}^{\pi}(H u)(s) u(s) d s=0 \text { for } \quad u \in L_{p}(-\pi, \pi), \quad p \geqq 2 .
$$

Amann's existence result in [1] for corresponding Hammerstein equations of form (5) with a strongly monotone Nemytskyi operator of $\varphi$ in $L_{2}(-\pi, \pi)$ seems to be the first application of monotone operator theory to nonlinear singular integral equations:

The equation

$$
\varphi(\cdot, u)+\lambda H u=g
$$

is equivalent to a Riemaǹn-Hilbert problem for a holomorphic function $w=u+i v$ in the unit disk. Such nonlinear. Riemann-Hilbert problems are treated by methods of monotone operator theory in [24, 25]. In [24] the analogon to the existence theo: rem for the equation (7) is given, whereas in [25] the equation (11) with $\lambda= \pm 1$ and a monotone C-function $\varphi$ satisfying the inequality

$$
\text { r }|\varphi(s, u)| \leqq A(s)+B|u| .
$$


with $A \in L_{2}(-\pi, \pi), B>0$ and possessing limit functions

$$
\varphi_{ \pm}(s)=\lim _{u \rightarrow \pm \infty} \varphi(s, u)
$$

is studied in $L_{2}(-\pi ; \pi)$ by means of abstract Landesman-Lazer theorems of Brézis 'and Haraux, and de Figueiredo, respectively.

\section{b) Integro-differential equations}

Let again the monotone C-function $\psi(x, u)$ satisfy the assumptions (3), (4) with $p \geqq 2$ instead of $q$, the monotone C-function $\chi(x, u)$ fulfil the condition $\psi(\cdot, c) \in L_{q}$ for each $c \in \mathbf{R}$, and let $\beta$ be a nonnegative bounded measurable function on $[-a, a]$. Then the integro-differential equation

$$
u^{\prime}+\beta u+\chi(\cdot, u)+\psi(\cdot, u)+\lambda S u=g
$$

for $\lambda \in \mathbf{R}, g \in L_{q}$ has a solution $u \in L_{p}$ with $u^{\prime} \in L_{q}$ satisfying one of the conditions $u(-a)= \pm u(a)$ or $u(-a)=0$, respectively [26].1) The proof again.uses the main theorem of maximal monotone operators.

The theory of maximal monotone operators can also be utilized to prove the existence of solutions to some nonlinear generalizations of the well-known Prandtl's integro-differential equation of airfoil theory [26]. For instance, the equation

$$
\Phi(\cdot, u)+\lambda S u+T u=g,
$$

where $\hat{\lambda} \in \mathbf{R}, g \in L_{2}(r), \Phi(x, u)$ is a monotone C-function satisfying the inequality

$$
|\Phi(x, u)| \leqq A(x)+B r^{-1}(x)|u|
$$

with $A \in L_{2}(r), B>0$ and $T u=-S u^{\prime}$, has a unique solution $u \in L_{2}\left(r^{-1}\right)$ with $u^{\prime} \in L_{2}(r)$ which fulfils the boundary conditions $u( \pm a)=0$. The function $\Phi$ need not satisfy the corresponding coercivity condition. since the operator $T$ is positive definite:

$$
(T u, u) \geq \int_{-a}^{a} r^{-1}(x) u^{2}(x) \overline{d x}
$$

for any $u \in L_{2}\left(r^{-1}\right)$ with $u( \pm a)=0$ and $u^{\prime} \in L_{2}(r)$. Here the function $r$ is given by (10) again. An analogous theorem holds for the equation (14) with additional term $\mu u^{\prime}$, where $|\mu|<1$, and with coercive function $\Phi$ in corresponding spaces $L_{p}(\varrho), p>2[26]$.

Other types of singular integro-differential equations are studied in [17] by repucing them to operator equations containing the monotone operators

$$
\left.B_{1}=-S_{0}\left[J\left(x_{0}, C\right)\right]^{2}\right), \quad B_{2}=J(-a, 0)\left[r^{-1} S\right],
$$

where $J$ is the operator of integration

$$
\left(J\left(x_{0}, C\right) u\right)(x)=\int_{x_{0}}^{x} u(y) d y+C, \quad-a \leqq x_{0} \leqq \dot{a}
$$

1) In case of $u(-a) \stackrel{\doteq}{=} u(a)$ the function $\beta$ shall not vanish identically. The case $u(-a)=0$ not haindled in [26] can be dealt with as the other. cases there.

2) In [17] the minus sign in $B_{1}$ is missing. Therefore, in the sequel we will accordingly change the corresponding equations from [17]. 
The monotonicity of $B_{1}$ and $B_{2}$ from $L_{p}, p>1$ or $p>2$, respectively, into $L_{q}$ follow from (16) by corresponding substitutions $\left.{ }^{3}\right)$ :

$$
\left(B_{1} u, u\right)=(w, T w), \quad w=B_{1} u, \quad
$$

since $S S_{0} v=v-$ const for $v \in L_{p}, p>2$ (cf. [26]);

$$
\left(B_{2} u, r^{-1} u\right)=(\bar{w}, T w), \quad w^{\prime}=B_{2} u,
$$

in view of $(9)$, in both cases the conditions $w( \pm a)=0$ are fulfilled.

In this way the existence of absolutely continuous solutions $u$ in suitable $L_{p}$ spaces for $u$ and $u^{\prime}$ is proved for equations of the form

and

$$
\begin{aligned}
& u-\lambda S \varphi\left(\cdot, u^{\prime}\right)=f, \\
& r u^{\prime}+\lambda S \varphi(\cdot, u)=0, \quad u(-a)=0
\end{aligned}
$$

$$
u^{\prime}-\lambda \varphi\left(\cdot, S_{0} u\right)=g, \quad u\left(x_{0}\right)=c,
$$

where $\lambda>0$ in (17), $\lambda \geqq 0$ in (18), (19), and $\varphi$ is a monotone C-function satisfying conditions of the form (3), (4) [17]. Some further analogous existence theorems under weaker assumptions on $\varphi$ are stated in [20], especially for solutions $u$ with the side condition $(r, u)=m$ in the equation (18), where the term $r u^{\prime}$ is replaced by $u^{\prime}$ itself.

Integro-differential equations of the type

$$
u^{\prime}+\lambda H u+\varphi(\cdot, u)=g
$$

with the Hilbert operator $\boldsymbol{H}$ are equivalent to a generalized Steklov problem. for a holomorphic function $w=u+i v$ in the unit disk. In [24] the analogon to the existence theorem for the equation (13) and in [25] a corresponding LandesmanLazer theorem for functions $\varphi$ satisf ying $(12 \mathrm{a}, \mathrm{b})$ are given.

\section{Application of nonlocal implicit function theorem}

Existence theorems for the integral equation (5) and the integro-differential equation (17) were also obtained with the help of a nonlocal implicit function theorem derived by Magomedov in [16]. In [16] itself existence of a (unique) Hölder continuous solution $u$ of equation (5) with $f \equiv 0$ and $\lambda_{i} \in \mathbf{R}$ is proved if the function $\varphi$ has the form $\varphi=\varrho \Phi$ with some weight function $\varrho(x)$ and a Hölder continuous function $\Phi(x, u)$ possessing a Hölder continuous nonvanishing derivative $\Phi_{u}$ whose Hölder norm satisfies a Hölder condition and whose reciprocal $1 / \Phi_{u}$ obeys some weak growth condition.

Furthermore, the equation (17) with $\lambda>0$ and $f \in C$ has a unique solution $u \in C^{1}$ if the function $\varphi(x, v)$ is continuous and has a continuous derivative $\varphi_{v}>0$ whose reciprocal $1 / \varphi_{v}$ fulfils some weak growth condition $[17,18]$.

Finally, there exists a unique solution $u \in W_{2}^{1}$ to the equation (5) for any $\lambda \epsilon \mathbf{R}$, $f \in W_{2}{ }^{1}$ if the function $\varphi(x, u)$ has derivatives $\varphi_{u}, \varphi_{x}, \varphi_{u u}, \varphi_{x u}$, where $\varphi, \varphi_{u}, \varphi_{u u}$ are continuous functions with $\varphi_{u} \geqq 0$,

$$
\varphi( \pm a, u) \equiv \mathbf{0}
$$

3) Or may be directly shown as in [17] by means of trigonometrical Fourier expansion of $u$. 
and $|\varphi|, \varphi_{u},\left|\varphi_{x}\right|$, and $\left|\varphi_{x u}\right|$ satisfy. some growth conditions inplying powerlike behaviour of $\varphi$ with -respect to $u[18,19]$. Moreover, this existence theorem for the equation (5) can be extended to a related equation with $S$ replaced by the operator $K$ defined by

$$
(K u)(x)=\frac{1}{\pi} \int_{-a}^{a} \frac{k(x, y) u(y)}{y-x} d y
$$

where the kernel $k(x, y)$ is symmetric and possesses Hölder continuous first derivatives. Then the condition (21) can be' replaced by the condition $k(x, \pm a) \equiv 0$, too $[18,19]$.

\section{Application of Schauder's fixed point theorem}

\section{a) Completely continuous operator equations}

By means of. Schauder's fixed point theorem the existence of solutions of nonlinear integral' equations can be proved if the corresponding operator is completely continuous, i.e. continuous and compact, in the considered Banach space and, roughly speaking, the nonlinearity is sublinear. ${ }^{4}$ ) This is the case in Hölder spaces for the integral equation (5) with fixed singularity

$$
u(x)+\frac{1}{\pi} \int_{-a}^{a} \frac{\varphi(x, y, u(y))}{y-x_{0}} d y=f(x), \quad-a<x_{0}<a,
$$

if the function $\varphi(x, y, u)$ grows not faster than $|u|^{l}, l<1$, and fulfils a Hölder coudition in $x, y, u$ [15]. Further, by integration the integro-differential equations

$$
u^{\prime}=\lambda S \varphi(\cdot, u), \quad: u^{\prime}=\lambda \varphi(\cdot, S u)
$$

with the additional condition $u\left(x_{0}\right)=c,-a \leqq x_{0} \leqq a$, where $\lambda \in \mathbf{R}$ and $\varphi(x, u)$ is a C-function which again grows not faster than $|u|^{l}, l<1$, can be reduced to such an operator equation in $L_{p}, p>2[17]$.

\section{b) Quasilinear integro-dịferential equạtions}

The quasilinear integro-differential equation

$$
A(\cdot, u) u^{\prime}-S u^{\prime}=G(\cdot, u)
$$

with a continuous function $A(x, u)$ and a C-function $G(x, u)$ can be reduced to a fixed point equation for $u$ by solving (24) for given $A, G$ with respect to $u^{\prime}$ and integrating the obtained expression for $u^{\prime}$. This fixed point equation for $u$ in a formal way resembles the corresponding equations steming from integro-differential equations of the type

$$
u^{\prime}=\varphi(\cdot, u) \cdot \psi(\cdot, S u), \quad u^{\prime}=\varphi(\cdot, u) \cdot \psi\left(\cdot, S_{0} u\right)
$$

by integration.

4) In this situation also Kačurovskyi's theorem for asymptotically linear completely continuous operator equations may be applied. 
Equations of the form (25) occur by the treatment of free boundary problems in . the theory of jets. in hydrodynamics (cf. $[10,23])$. They can be, handled by means of the Schauder fixed point theorem in spaces of continuous or Hölder continuous functions using a.known lemma by Zygmund for estimating. Extending this approach, one obtains the existence of a solution $u \in W_{p}^{1}$ for some $p>1$ to equation (24) with $u(\mp a)=0$ if $A$ satisfies the inequality.

$$
-l_{1} \leqq A(x, u) \leqq l_{2}
$$

with finite $l_{k} \geqq 0, k=1,2$, and $l_{1} l_{2}<1$ and $G$ fulfils the estimation

$$
|G(x, u)| \leqq l_{0}\left(a^{2}-x^{2}\right)^{\dagger / \delta}
$$

with $l_{0} \geqq 0$ and $0 \leqq \delta<1 / 2$ [31]. This existence theorem can also be extended to quasilinear integro-differential equations of the more general form. (24)' with $A(\cdot, u, S u), \dot{G}(\cdot, u, S u)[32]$. We further remark that recently a particular equation of the second type (25) from hydrodynamics with positive functions $\varphi, \psi$ was dealt. with by Schauder's fixed point theorem in a subset of monotone Hölder continuous functions in $C$ [9].

Finally, corresponding quasilinear integro-differential equations to (24) with the Hilbert operator $H$ instead of $S$, naniely equations of the form .

$$
u^{\prime}+\dot{H}\left[M(\cdot, u) u^{\prime}\right]=g+\dot{H}[N(\cdot, u)]
$$

with one of the additional conditions

or

$$
u(0)=k
$$

$$
\frac{1}{2 \pi} \int_{-\pi}^{\pi} u(s) d s=m,
$$

have been dealt with in an analogous manner in [30].

\section{c) Integral equations}

Under suitable differentiability assumptions about $\varphi(x, u)$ the integral equation

$$
\varphi(\cdot, u)=S u+c
$$

for solutions $u \dot{\epsilon} W_{p}{ }^{x}, p>1$, with $u( \pm a)=0$ and a free constant $c$ is equivalent to the integro-differential equation (24), where $A=\varphi_{u}, G=-\varphi_{x}$. Therefore, the above-mentioned existence theorem for (24) immediately yields a such one for (30) [31]. The same is true for more general equations. of the form

$$
F(\cdot, u, S u)=c
$$

with a differentiable function $F(x, u, v)$ satisfying $F_{v} \neq 0$ [32].

Moreover, corresponding existence theorems can be proved in analogous way for Hammerstein equations of the form (5)

$$
u=S \varphi(\cdot, u)+f+c
$$

with a free constant $c$ under suitable additional sign conditions on the functions $\varphi( \pm a, u)$ and $\varphi_{u}( \pm a, u)$. Especially, if $(21)$ is fulfilled, the constant $c$ can be fixed, .i.e. $c=0$. without loss of generality [31]. This case corresponds to the above-men- 
tioned existence theorem for the equation (5) by means of the nonlocal implicit function theorem of MAGOMEDOv in [18].

We further remark that on the right-hand side of (32) additional integral terms of the form

$$
\frac{1}{\pi} \int_{-a}^{a} \psi(y, u(y)) \ln |y-x| d y+\int_{-a}^{a} \chi(x, y, u(y)) d y
$$

can be present, where the condition (27) has to hold for the sum $\psi+\varphi_{x}$ instead for $\varphi_{x}$, and $\chi(x, y, u)$ is a C-function possessing a derivative $\chi_{x}$ which satisfies an estimation

$$
\left|\chi_{x}(x, y, u)\right| \leqq \gamma(y)\left(a^{2}-x^{2}\right)^{-s}
$$

with $0 \leqq \delta<1 / 2$ and $\gamma \in L_{1}$.

In an analogous way the integral equation

$$
u+H \varphi(\cdot, u)+K \psi(\cdot, u)=f
$$

with the integral operator

$$
(K v)(s)=\frac{1}{2 \pi} \int_{-\pi}^{\pi} v(\sigma) \ln \left(4 \sin ^{2} \frac{\sigma-s}{2}\right) d \sigma
$$

and differentiable functions $\varphi, f$ can be reduced to the integro-differential equation (28) with (29b), where $M=\varphi_{u}, N=\psi-\varphi_{s}, g=f^{\prime}$ and

$$
\left.m=\frac{1}{2 \pi} \int_{-\pi}^{\pi} f(s) d s .{ }^{5}\right)
$$

In particular, in this way the existence of a solution to the known. Theodorsen integral equation of conformal mapping (cf. [11]) for a smooth starlike Jordan curve has been proved independently of Riemann's mapping theorem [30].

Finally, we remark that by a similar approach related nonlinear Riemann-Hilbert problems for holomorphic functions have been dealt with in $[28,29]$.

\section{d) Reduction to quasilinear Beltrami equation}

The integral equation (30) for functions $\varphi$ of the form

$$
\varphi^{\prime}(x, u)=b_{0}(x)+b_{1}(x) u+\psi(u)
$$

with Hölder continuous functions $b_{k}, k=0 ; 1$, and a function $\psi$ possessing a bounded measurable derivative $\psi^{\prime}$ can be reduced to a boundary value problem for the solution of a quasilinear complex elliptic differential equation of Beltrami type with a linear Riemann-Hilbert boundary condition in the upper half-plane [31]. Existence theorems for the Riemann-Hilbert problem of the Beltrami equation have been given by Monaorov [21] and others.

In an analogous way such a reduction to a linear Riemann-Hilbert problem for a quasilinear Beltrami equation can be done for the integral equation (11), cf. [29] for the reduction of the nonlinear Riemann-Hilbert problem for holomorphic functions equivalent to (11):

5). Knownly, for the operator (34) the relations $[K v]^{\prime}=-H v$ and $\int_{-\pi}^{\pi}(K v)(s) d s=0$ hold. 


\section{REFERENCES}

[1]. AMavN, H.: Uber die Existenz und iterative Berechnung einer Lösung der Hammersteinschen Gleichung. Aequat. Math. 1 (1968), 242-266.

[2] Асхавов, С. Н.: О применимости метода монотонных операторов-к нелинейным сингулярным уравнениям в $L_{2}(-\infty, \infty)$. Докл. Акад. Наук Азерб. ССР 36 (1980) $7,28-31$.

[3] Асхавов, С. Н.: О применимости метода монотонных операторов к нелинейным сингулярным интегральным уравнениям и их системам в $L_{2, n}(-\infty, \infty)$. Гросный 1980,17 стр. (Деп.. В ВИНИТИ' 1980).

[4] Асхавов, С. Н.: Применение метода монотонных операторов к нелинейным сингуляриым интегральным уравпениям и их системам в $L_{p, n}(\varrho)$. Гросный 1980,20 стр. (Деп..в ВИНИТИ 1980).

[5] Асхавов, С. Н.: Исследование нелинейых сингулярных интегральных уравиений методом монотонных операторов. Изв. Северо-Кавказ. Научн. Центра Высш. Шиолы, Естеств. Науки (1980) 2, 3-5.

[6] Асха вов, С. Н.: ГІрименение метода монотонных операторов к некоторым классам нелинениы сингулярных интегральных уравнений и их системам в $L_{p, n}(\varrho)$. Гросныю 1981, 28 стр. (Деп. в ВИНИТИ 1981).

[7] Асха вов, С. Н.: Применение метода монотонных операторов к некоторым незинеиным уравнениям типа свертки и сингуляриым интегральным уравніения. Изв. Высші. Учебн. Завед., Матем. (1981) 9, 64-66.

[8] Асха́вов, С. Н., и Х. Ш. Мухтаров: Метод монотонных операторов в теории нелинейных сингулярных интегральных уравненй. Гросный 1982,14 стр. (Деп. в ВИНИТИ 1983).

[9] БАьАев, А. А.: О разрешимости одноЙ нелинейной краевой задачи аналитических функций. Изв. Высш. Учебн. Завел., Матем. (1978) 6, 27-35.

[10] Breknofr, G., and E. H. Zarantonello: Jets, Wakes, and Cavities. New York: Academic Press 1957.

[11] GaIER, D.: Konstruktive Methoden der konformen Abbildung. Berlin-Göttingen-Heidelberg: Springer-Verlag 1964.

[12] Гусейов, А. И., и Х. Ш. Мухтаров: Применение метода монотонных операторов' к одному классу интегральных уравненић. Докл. Акад. Наук Азерб. ССР 35 (1979) $8,3-6$.

[13] Гусейнов, А. И., и Х. Ш. Мухтаров: Введение в теорию нелинейных сингуляриых интегральных уравнении. Москва: Изд-во Наука 1980.

[14] Иманалиев, М. И.; ХведелидЗЕ, Б. В.; ГеГЕлия, Т. Г.; БабАев, А. А., И А. И. БотАшев: Иитегральные уравнения. Дифф. Урави. 18 (1982), 2050-2069.

[15]. Магомедов, l'. М.: Об интегральных уравнениях с неподвижной сингулярностью. Докл. Акад. Наук СССР 209 (1973), 548-550.

[16] МАгомедов, Г. М.: Нелокальная теорема о неявной фуниции и ее применение к нелинен̆ому сингулярному интегральному уравнению. Докл. Акад. Наук СССР 212 (1973), 1056- 1058 .

[17] МаГомедов, Г. М.: Метоп монотонности в теории нелинейых сингулярных интегральных и интегро-лифференциалыых уравнений. Дифф. Уравн. 13 (1977), $1106-1112$.

[18] Магомедов, Г. М.: Метод априорных оценок для нелинейых уравненин. с сингулярными интегралами. Докл. Акад. Наук СССР 253 (1980), 292-294.

[19] Магомедов, Г. М.: Исследование нелинейных синулярных интегральных уравнений без ограничени на параметр. Махачкала 1980, 11 стр. (Деп. в ВИНИТИ 1980).

[20] МАгомедов, Г. М., и С. Н. ДжАлалова: О некоторыХ классах нелиненй сингулярных интегродифференциальных уравнений. Докл., Акад. Наук С́ССР 270 (1983), 788-791.

[21] Монахон, В. Н.: Краепые аадачи со свободными границами для эллиптических систем уравнений. Новосибирск: Иад-во Наука 1977.

[22] Pogonzelski, W.: Integral Equations and their Applications. Oxford: Perganion Press 1966, and Warsaw: PWN.Pol. Scient. Publ. 1966. 
[23] Пыхте́в, Г. Н.: О̄бщая и основная краевые задачи плоских струйных установившихся теченй и соответствующие им нелинейные уравнения. Прикл. Матем. Техн. Физ. 1 (1966), 32-44.

[24] v. WOLFERSDORF, L.: Monotonicity methods for two classes of nonlinear boundary value problems with semilinear first order elliptic systems in the plane. Math. Nachr. 109 (1982), 215-238.

[25] v. WolfFrendoRf, 1.: Landesman-Lazer's type boundary value problems for holomorphic functions. Math. Nachr. 114 (1983), $181-189$.

[26] v. WOLFERSDORF, 1..: Monotonicity methods for nonlinear singulàr integral and integrodifferential equations. ZAMM 63 (1983), 249-259.

[27] v. WOLFERSDORF, L.: On a.class of nonlinear singular integral equations. ZAMM 65 (1985), $309-310$.

[28] v. WolfERSDORF, L.: A class of nonlinear Riemann-Hilbert problemens for holomorphic functions. Math. Nachr. 116 (1984), 89-107.

[29] v. WolfFrsDorf, L.: On the theory of the nonlinear -Riemann-Hilbert problem for holomorphic functions. Complex Variables 3 (1984), 457-480.

[30] v. WoLteqrsuorf, L.: A Cliss of Nonlinear Singúlar Integral and Integro-Differential Equations with Hilbert Kernel. Z. Anal. Anw. 4. (1985), 385-401.

[31] v. WOLFERSDOKF, L.: On the theory of nonlinear singular integral equations of Cauchy type. Math: Meth. Appl. Sci. 7 (1985).

[32] v. Wolfersdorf, L., and J. Woíska-Bochenek: A mixed nonlinear Riemann-Hilbert problem for analytic functions in the halfplane. Demonstratio Mathematica (to a ppear).

Manuskripteingang: 14. 12. 1984

\section{VERFASSER :}

Prof. Dr. Lothar v. Wolfersdorf

Sektion Mathematik der Bergakadêmic Freiberg

DDR - 9200 Freiberg; Bernhard-v.-Cotta-Str. 2 